\title{
Estimation Method of Oil Displacement Efficiency Based on Standard Core Analysis
}

\author{
Gladkikh E.A. \\ Oil and Gas Technologies Department \\ Perm National Research Polytechnic University \\ Perm, Russia \\ gladkih.ea@mail.ru
}

\author{
Khizhniak G.P. \\ Oil and Gas Technologies Department \\ Perm National Research Polytechnic University \\ Perm, Russia \\ xgp@mail.ru
}

\author{
Galkin V.I. \\ Oil and Gas Geology Department \\ Perm National Research Polytechnic University \\ Perm, Russia \\ vgalkin@pstu.ru
}

\begin{abstract}
The article is dedicated to the estimation of oil displacement efficiency. It is obligatory for the estimation of mineable reserves, feasibility study of oil recovery efficiency and control of the field development. The complexity of its laboratory determination is caused by the labor intensity and duration of experiments. When the amount of core is insufficient for the filtration experiments or there is no core at all, the displacement efficiency is estimated either by analogy with the neighboring fields or by analytical dependences which are crucial. During the generalization and analysis of some considerable amount of the experimental data, the authors have developed the method of oil displacement efficiency estimation without its laboratory determination. The proposed method is based on the use of the data from the previously conducted researches to develop the statistical models of the displacement efficiency estimation with the use of the linear stepwise regression and discriminatory analyses. To implement the method, it is required to know the reservoir properties, along with oil viscosity, such as porosity, permeability, residual water saturation and volume density of rocks during the standard core analysis. The article includes the main stages of the method implementation for the Bashkir carbonate and Visean terrigenous sediments in the deposits of the Bashkir formation of Perm Region. In the course of the initial data analysis, it has been established that there are certain categories of values, for which the regression equations are statistically substantiated. They demonstrate a great similarity of the model and the experimental values of the displacement efficiency.
\end{abstract}

Keywords-component; displacement efficiency, reservoir properties, regression equation, carbonate deposits.

\section{INTRODUCTION}

The displacement efficiency (ED) determination is mandatory for the estimation of mineable reserves, feasibility study of oil recovery efficiency and control of field developments. All these processes require the implementation of labour intensive, complicated and long lasting laboratory experiments with the use of real cores and reservoir fluids in the conditions simulating their natural occurrence [1-5].
When a laboratory determination of the displacement efficiency is impossible, its value is estimated either by analogue with the neighbouring fields [6] or by analytical dependences [7], while the latter is the priority objective.

The displacement efficiency has been studied for about fifty years, which has made it possible to accumulate a considerable amount of the experimental data in Perm Region, including more than 1,100 laboratory based experiments for 170 fields and 400 productive formations. Such statistical data can serve as the basis in creating the models enabling the displacement efficiency evaluation.

The authors have proposed the method which allows estimating the displacement efficiency to a high precision without its laboratory determination by using the parameter values determined during the standard core analysis [8], as well as the available values of oil viscosity. The article includes the main stages of the method implementation for oil deposits in the Bashkir carbonate and Visean terrigenous sediments in the deposits of the Bashkir formation of Perm Region. This method has made it possible to statistically substantiate the regression equations for the displacement efficiency estimation.

\section{GEOLOGICAL SETTING OF THE RESEARCH TARGET}

The Visean terrigenous oil and gas bearing complex contains the deposits of the Malinov, Tula, and Bobrikov horizons, and it is of a special importance for the oil industry of Perm Region. More than half of the discovered oil resources of this territory are connected to these deposits. The deposits of the Visean oil are found in 134 oil reserves out of 176 ones that were developed (as of January 01, 2015), while 46 of them are located on the territory of the Bashkir formation. Geological and physical conditions can differ greatly within the Bashkir formation, for example, porosity and gas permeability (by core samples) vary from 0.153 to 0.251 unity fraction (u.f.) and from 0.0245 to $3.19 \mu \mathrm{m}^{2}$, 
respectively; and oil viscosity varies from 1.87 to $50 \mathrm{mPa} \bullet \mathrm{s}$. The general tendency is that the viscosity within the Bashkir formation increases from North to South and from East to West.

Within the Solikamsk depression, the porosity of the Visean oil reservoirs varies from 0.092 to 0.195 u.f., and the gas permeability varies from 0.0126 to $0.922 \mu \mathrm{m}^{2}$. The oil is light and low-viscous compared to the majority of the Bashkir formation oil, the viscosity varies from 0.75 to $6.6 \mathrm{mPa} \bullet \mathrm{s}$.

Bashkir carbonate deposits are ranked second in terms of the volume of hydrocarbon deposits on the territory of the region. Oil deposits are found in 77 fields being developed, and 21 of them are located within the Bashkir formation. The porosity of the Bashkir reservoir rocks within this formation varies from 0.124 to 0.226 u.f., the gas permeability varies from 0.0214 to $0.576 \mu \mathrm{m}^{2}$. On average, the Bashkir oil of the similarly named formation is lighter than the Visean one, and the viscosity varies from 5.7 to $16.4 \mathrm{mPa} \cdot \mathrm{s}$.

Productive sediments of the Solikamsk depression deposits are characterized by lower values of porosity $0.114 \ldots 0.170$ u.f., gas permeability of $0.0062 \ldots 0.180 \mu \mathrm{m}^{2}$ and oil viscosity of $0.88 \ldots 13 \mathrm{mPa} \cdot \mathrm{s}$.

\section{DEVELOPMENT OF STATISTICAL MODELS FOR THE DISPLACEMENT EFFICIENCY ESTIMATION IN PRODUCTIVE SEDIMENTS OF THE BASHKIR FORMATION}

Bashkir carbonate deposits

To develop the statistical models, the authors have used the results of the laboratory studies of the displacement efficiency in productive sediments of the Bashkir carbonate deposits of the Bashkir formation of Perm Region, as well as the respective parameters describing the porosity and permeability properties of the reservoir rocks, such as gas permeability $\left(\mathrm{F}_{\mathrm{gp}}\right)$, porosity $\left(\mathrm{F}_{\mathrm{p}}\right)$, residual water saturation $\left(F_{\text {rws }}\right)$, volume density of rocks $(\rho)$ and oil viscosity $\left(\mu_{\text {oil }}\right)$. The said parameters for the complex model of the formation are gained by their averaging based on single core samples which had formed this model. These averaged values together with the values of ED determined during the laboratory tests are given in Table 1. To ensure a complex consideration of the parameters, the table also includes the ratios of the gas permeability and oil viscosity $\left(\mathrm{F}_{\mathrm{gp}} / \mu_{\mathrm{oil}}\right)$, as well as porosity and density $\left(\mathrm{F}_{\mathrm{p}} / \rho\right)$. The whole sample (Table 1$)$ was ranked in an ascending order for the value of the displacement efficiency. The methods of regression and discriminatory analyses are applied in order to carry out the core studies [9, 10]. The correlation fields are drawn up for all the parameters; and the values of correlation coefficients $r$ (Table 2) are calculated.

The data in Table 2 proves that $\mathrm{F}_{\text {rws }}$ exerts a considerably strong statistical influence on ED, i.e. the oil displacement efficiency increases with the increase of the initial hydrocarbon saturation of rocks.
TABLE 1. SUMMARIZED DATA OF LABORATORY ESTIMATIONS OF THE DISPLACEMENT EFFICIENCY IN CARBONATE ROCKS OF THE BASHKIR HORIZON IN THE DEPOSITS OF THE BASHKIR FORMATION

\begin{tabular}{|c|c|c|c|c|c|c|c|c|c|}
\hline $\mathrm{Nr}$ & Field & $\begin{array}{l}F_{p} \text {, } \\
\text { u.f. }\end{array}$ & $\begin{array}{l}F_{g p}, \\
\mu m^{2}\end{array}$ & $\begin{array}{l}\text { F }_{\text {rwws }} \text {, } \\
\text { u.f. }\end{array}$ & $\underset{\mathrm{g} / \mathrm{cm}^{3}}{\mathbf{p}}$ & $\underset{\mathrm{mPa} \cdot \mathrm{s}}{\mu_{\text {oil }},}$ & $\begin{array}{c}\mathbf{F}_{\mathrm{p}} / \mathbf{p} \\
\mathbf{c m}^{3} / \mathrm{g}\end{array}$ & $\begin{array}{c}\mathrm{F}_{\mathrm{gp}} / \boldsymbol{\mu}_{\text {oil }}, \\
\boldsymbol{\mu \mathrm { m } ^ { 2 } /} \\
\mathrm{mPa} \cdot \mathrm{s}\end{array}$ & $\begin{array}{l}E_{D} \text {, } \\
\text { u.f. }\end{array}$ \\
\hline 1 & Pavlovsky & 0.128 & 0.0214 & 0.264 & 2.36 & 15.4 & 0.0542 & 0.0014 & 0.487 \\
\hline 2 & Pavlovsky & 0.137 & 0.0647 & 0.282 & 2.34 & 15.4 & 0.0585 & 0.0042 & 0.499 \\
\hline .. & $\ldots$ & $\ldots$ & $\ldots$ & $\ldots$ & $\ldots$ & $\ldots$ & $\ldots$ & $\ldots$ & $\ldots$ \\
\hline 18 & Chernushka & 0.162 & 0.0987 & 0.159 & 2.24 & 9.1 & 0.0723 & 0.0108 & 0.612 \\
\hline 19 & Kalmiyarsk & 0.226 & 0.5760 & 0.122 & 2.09 & 13.95 & 0.1081 & 0.0413 & 0.620 \\
\hline
\end{tabular}

TABLE 2. CORRELATION MATRIX FOR THE SAMPLES OF THE BASHKIR CARBONATE DEPOSITS

\begin{tabular}{|c|c|c|c|c|c|c|c|c|}
\hline & $\mathbf{F}_{\mathbf{p}}$ & $\mathbf{F}_{\mathbf{g p}}$ & $\mathbf{F}_{\text {rws }}$ & $\mathbf{p}$ & $\boldsymbol{\mu}_{\text {oil }}$ & $\mathbf{F}_{\mathbf{p}} / \mathbf{p}$ & $\mathbf{F}_{\mathbf{g p}} / \boldsymbol{\mu}_{\text {oil }}$ & $\mathbf{E}_{\mathbf{D}}$ \\
\hline $\mathbf{F}_{\mathbf{p}}$ & 1.00 & 0.68 & -0.56 & -0.97 & -0.26 & 0.98 & 0.70 & 0.41 \\
\hline $\mathbf{F}_{\mathbf{g p}}$ & & 1.00 & -0.54 & -0.68 & 0.00 & 0.75 & 0.86 & 0.41 \\
\hline $\mathbf{F}_{\mathbf{r w s}}$ & & & 1.00 & 0.57 & 0.10 & -0.56 & -0.45 & -0.75 \\
\hline $\mathbf{p}$ & & & & 1.00 & 0.35 & -0.97 & -0.73 & -0.50 \\
\hline $\boldsymbol{\mu}_{\text {oil }}$ & & & & & 1.00 & -0.27 & -0.44 & -0.16 \\
\hline $\mathbf{F}_{\mathbf{p}} / \mathbf{p}$ & & & & & & 1.00 & 0.77 & 0.45 \\
\hline $\mathbf{F}_{\mathbf{g p}} / \boldsymbol{\mu}_{\mathbf{o i l}}$ & & & & & & & 1.00 & 0.38 \\
\hline $\mathbf{E}_{\mathbf{D}}$ & & & & & & & & 1.00 \\
\hline
\end{tabular}

Note: In the table cells, the value of the correlation coefficient is shown in the numerator and the value of the statistical significance $(p)$ is shown in the denominator. The statistically significant correlation coefficients (for which $p<0.05$ ) are shown in red.

It is also worth mentioning that some parameters correlate well with each other; and it does not contradict their physical meaning. Thus, the authors can build the multilevel equation using the method of the stepwise regression analysis, where $\mathrm{ED}$ is a dependent variable, and all other parameters, characterizing porosity and permeability properties, as well as oil properties, are the independent variables. The values of the regression coefficients are found by the least square method. The resulting equation is as follows:

$\mathrm{ED}^{\mathrm{M}}=1.9274-0.6199 \mathrm{~F}_{\text {rws }}-0.4852 \rho-2.0792\left(\mathrm{~F}_{\mathrm{p}} / \rho\right)$

where $\mathrm{R}^{2}=0.64$ and $\mathrm{p}<0.0014, \mathrm{~N}=19$, where $\mathrm{R}^{2}$ is the determination coefficient, $\mathrm{p}$ is the level of statistical significance, if $\mathrm{p}<0.05$, the value is statistically significant, $\mathrm{N}$ is the sample size.

The obtained equation confirms the conclusion which has been made for the correlation matrix with regard to the influence of $\mathrm{F}_{\mathrm{rws}}$ on the oil displacement efficiency.

Based on the correlation field of the model and experimental values of ED (Fig. 1a), it is obvious that it consists of two parts. When the values of the oil displacement efficiency are less than 0.56 , the model and actual values of the coefficient control each other quite well. When the values of the oil displacement efficiency are more than 0.56 , the model values vary insignificantly. It allows making a conclusion about the inhomogeneity of the sample and the presence of separate groups of values.

To confirm this conclusion, the linear discriminant analysis is applied. The resulting linear discriminant function that subdivides the initial sample in Table 1 into two categories is as follows: 


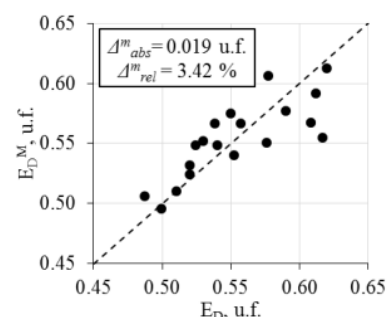

a)

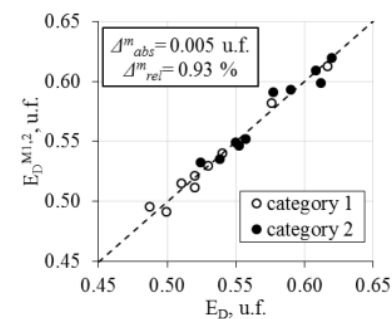

b)
Fig. 1. Comparison of the experimental and model values of the displacement efficiency before (a) and after (b) the subdivision into the sample categories of the Bashkir carbonate deposits of the Bashkir formation $\left(\Delta^{\mathrm{m}}{ }_{\mathrm{abs}}\right.$ is the mean absolute deviation, $\Delta^{\mathrm{m}}$ rel is the mean relative deviation).

$\mathrm{Z}=96.2606+48.8722 \mathrm{~F}_{\mathrm{rws}}-41.1925 \rho-78.8568 \mathrm{~F}_{\mathrm{p}}$, where $\mathrm{R}^{2}=0.77$ and $\mathrm{p}<3 \cdot 10^{-5}$

When $Z>0$, the data pertain to the first category; when $\mathrm{Z}<0$, the data pertain to the second category.

To evaluate the oil displacement efficiency in the Bashkir productive sediments of the Bashkir formation, the authors obtained the following equations with high values of $\mathrm{R}^{2}$ :

- for the first category

$\mathrm{E}_{\mathrm{D}}^{\mathrm{M} 1}=6.2282-0.5105 \mathrm{~F}_{\mathrm{rws}}+0.0122 \mu_{\mathrm{oil}}-2.2167 \rho-$

$$
-4.3314 \mathrm{~F}_{\mathrm{p}}
$$

where $\mathrm{R}^{2}=0.98$ and $\mathrm{p}<0.0014$;

- for the second category

$$
\begin{aligned}
\mathrm{E}_{\mathrm{D}}^{\mathrm{M} 2}= & 1.9903-0.0076 \mu_{\text {oil }}+0.1579 \mathrm{~F}_{\mathrm{gp}}-1.4349 \mathrm{~F}_{\mathrm{p}}- \\
& -0.4935 \rho,
\end{aligned}
$$

where $\mathrm{R}^{2}=0.95$ and $\mathrm{p}<0.0021$.

The comparison of the experimental and model values of ED calculated according to the equations (3) and (4) (Fig. 1b) shows that they control each other quite well $(r=0.99)$. Meanwhile the relative error of ED estimation decreased by 3.7 times, as compared with the variant without the subdivision into the categories.

\section{$\underline{\text { Visean terrigenous sediments }}$}

The initial sample was drawn up for the Visean terrigenous sediments (Table 3), which covers 27 fields of the Bashkir formation, by using the $71^{\text {st }}$ laboratory determination of the recovery factor.

According to this data, the authors drew up the correlation fields and determined $r$ correlation coefficients (Table 4). From Table 4, it is obvious that practically all the considered parameters correlate with each other quite well except for the two pairs of relations, i.e. the oil viscosity and residual water saturation, the oil viscosity and displacement efficiency, for which there is no statistically significant relation.

Based on the sample data from the stepwise regression analysis, the multilevel equation was drawn up to evaluate the model values of the displacement efficiency:

$\mathrm{E}_{\mathrm{D}}^{\mathrm{M}}=0.6056+0.0265 \mathrm{~F}_{\mathrm{gp}}-0.3229 \mathrm{~F}_{\mathrm{rws}}+0.1921\left(\mathrm{~F}_{\mathrm{gp}} / \mu_{\mathrm{oil}}\right)$
TABLE 3. SUMMARIZED DATA OF THE LABORATORY DETERMINATION OF THE DISPLACEMENT EFFICIENCY IN

\begin{tabular}{|c|c|c|c|c|c|c|c|c|c|}
\hline $\mathrm{Nr}$ & Field & $\begin{array}{l}F_{p}, \\
\text { u.f. }\end{array}$ & $\begin{array}{l}\mathrm{F}_{\mathrm{gp}} \\
\mu \mathrm{m}^{2}\end{array}$ & $\begin{array}{l}\text { F }_{\text {rws, }} \\
\text { u.f. }\end{array}$ & $\underset{g / \mathrm{cm}^{3}}{\mathrm{p}}$ & $\begin{array}{c}\mu_{\text {oil }}, \\
\mathbf{m P a} \cdot \mathbf{s}\end{array}$ & $\begin{array}{l}F_{\mathrm{p}} / \mathrm{p}, \\
\mathrm{cm}^{3} / \mathrm{g}\end{array}$ & $\begin{array}{c}\mathbf{F}_{\mathrm{gp}} / \boldsymbol{\mu}_{\mathrm{oil}}, \\
\boldsymbol{\mu m}^{2} / \\
\mathrm{mPa} \cdot \mathrm{s}\end{array}$ & $\begin{array}{l}E_{\mathrm{D}} \\
\text { u.f. }\end{array}$ \\
\hline 1 & Byrkinsky & 0.166 & 0.1130 & 0.226 & 2.16 & 8.40 & 0.0769 & 0.01345 & 0.500 \\
\hline 2 & Trifonovsky & 0.174 & 0.0245 & 0.461 & 2.17 & 5.37 & 0.0802 & 0.00456 & 0.500 \\
\hline 3 & Kalmiyarsky & 0.163 & 0.0461 & 0.179 & 2.22 & 8.20 & 0.0734 & 0.00562 & 0.526 \\
\hline 4 & Gondyrevsky & 0.222 & 0.2058 & 0.100 & 2.06 & 10.30 & 0.1078 & 0.01998 & 0.527 \\
\hline 5 & Yuzhinsky & 0.189 & 0.1124 & 0.111 & 2.15 & 11.70 & 0.0879 & 0.00961 & 0.528 \\
\hline$\cdots$ & 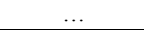 & $\cdots$ & $\cdots$ & $\cdots$ & $\cdots$ & . & $\cdots$ & $\cdots$ & $\ldots$ \\
\hline 71 & $\begin{array}{l}\text { Krasnoyarsky- } \\
\text { Kudinsky }\end{array}$ & 0.229 & 3.1900 & 0.040 & 2.03 & 13.10 & 0.1128 & 0.24351 & 0.720 \\
\hline
\end{tabular}
CARBONATE ROCKS OF THE VISEAN TERRIGENOUS SEDIMENTS IN THE DEPOSITS OF THE BASHKIR FORMATION

TABLE 4. CORRELATION MATRIX FOR THE SAMPLES FROM THE

\begin{tabular}{|c|c|c|c|c|c|c|c|c|}
\hline & $F_{p}$ & $F_{g p}$ & $\mathbf{F}_{\mathrm{rws}}$ & p & $\mu_{\text {oil }}$ & $F_{p} / p$ & $\mathbf{F}_{\mathrm{gp}} / \boldsymbol{\mu}_{\text {oil }}$ & $\mathbf{E}_{\mathbf{D}}$ \\
\hline $\mathbf{F}_{p}$ & 1.00 & $\frac{0.68}{0.000}$ & $\frac{-0.60}{0.000}$ & $\frac{-0.94}{0.000}$ & $\frac{0.37}{0.002}$ & $\frac{0.99}{0.000}$ & $\frac{0.31}{0.009}$ & $\frac{0.58}{0.000}$ \\
\hline$F_{g p}$ & & 1.00 & $\frac{-0.53}{0.000}$ & $\frac{-0.70}{0.000}$ & $\frac{0.37}{0.000}$ & $\frac{0.70}{0.000}$ & $\frac{0.53}{0.000}$ & $\frac{0.68}{0.000}$ \\
\hline $\mathbf{F}_{\mathrm{rws}}$ & & & 1.00 & $\frac{0.57}{0.000}$ & $\frac{-0.19}{0.115}$ & $\frac{-0.60}{0.000}$ & $\frac{-0.40}{0.001}$ & $\frac{-0.68}{0.000}$ \\
\hline p & & & & 1.00 & $\frac{-0.36}{0.000}$ & $\frac{-0.96}{0.000}$ & $\frac{-0.35}{0.003}$ & $\frac{-0.58}{0.000}$ \\
\hline$\mu_{\text {oil }}$ & & & & & 1.00 & $\frac{0.38}{0.001}$ & $\frac{-0.36}{0.002}$ & $\frac{-0.05}{0.683}$ \\
\hline $\mathbf{F}_{\mathrm{p}} / \mathbf{c}$ & & & & & & 1.00 & $\frac{0.32}{0.007}$ & $\frac{0.59}{0.000}$ \\
\hline $\mathbf{F}_{\mathrm{gp}} / \boldsymbol{\mu}_{\mathrm{oil}}$ & & & & & & & 1.00 & $\frac{0.66}{0.000}$ \\
\hline $\mathbf{E}_{\mathbf{D}}$ & & & & & & & & 1.00 \\
\hline
\end{tabular}
VISEAN TERRIGENOUS SEDIMENTS DEPOSITS OF THE BASHKIR FORMATION

where $\mathrm{R}^{2}=0.69, \mathrm{p}<10^{-5}, \mathrm{~N}=71$.

The order of the parameters in the regression equation is determined by the degree of their influence on the displacement efficiency. Thus, in equation (5), the value of $\mathrm{ED}^{\mathrm{M}}$ is formed, first of all, under the influence of the gas permeability of rocks, then there is the influence of the residual water saturation value and the relation $\mathrm{F}_{\mathrm{gp}} / \mu_{\mathrm{oil}}$.

The comparison of the model and experimental values of ED is given in Fig. 2.

Conditionally, three ranges of values can be singled out in the figure, such as

the one which is located to the left of the red rectangle, the model values of $\mathrm{ED}$ exceed the experimental ones;

the one which is located to the right of the red rectangle, the model values of $\mathrm{E}_{\mathrm{D}}$ are below the experimental ones;

- the one which is located within the red rectangle, where the model and actual values of $E_{D}$ poorly correlate with each other. Therefore, we can suggest that the value of the displacement efficiency from the outlined categories is influenced by different factors.

- To confirm this assumption, the correlation dependences of the reservoir properties were studied in more detail. Thus, based on the dependence of the mobility ratio $\left(R_{\mathrm{mob}}=\mathrm{F}_{\mathrm{gp}} / \mu_{\mathrm{oil}}\right)$ on the oil viscosity (Fig. 3), the authors can outline three categories of values as well, such as: 


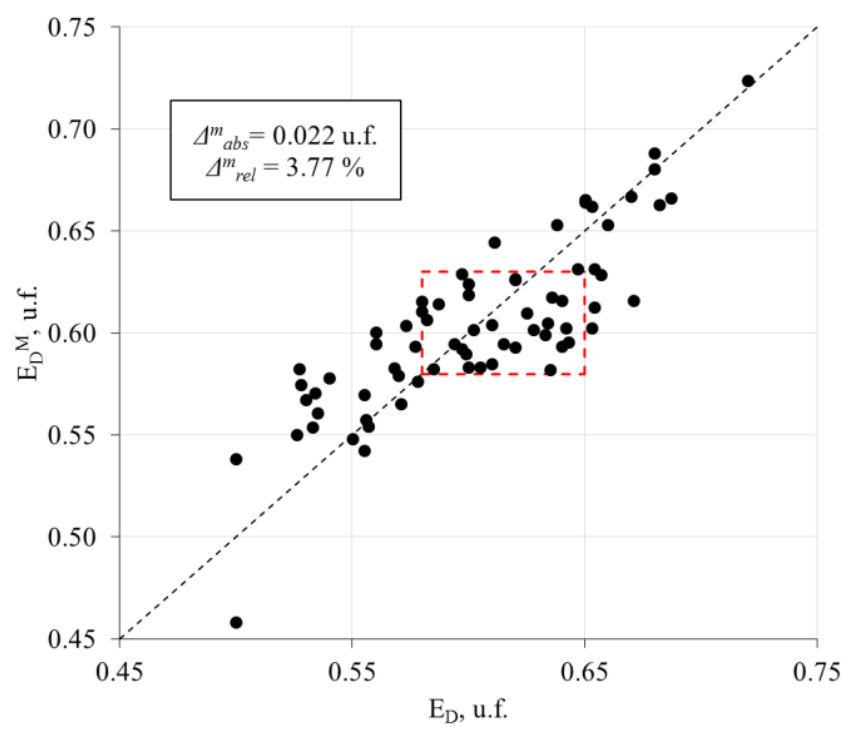

Fig. 2. The correlation field of the ED model and experimental values.

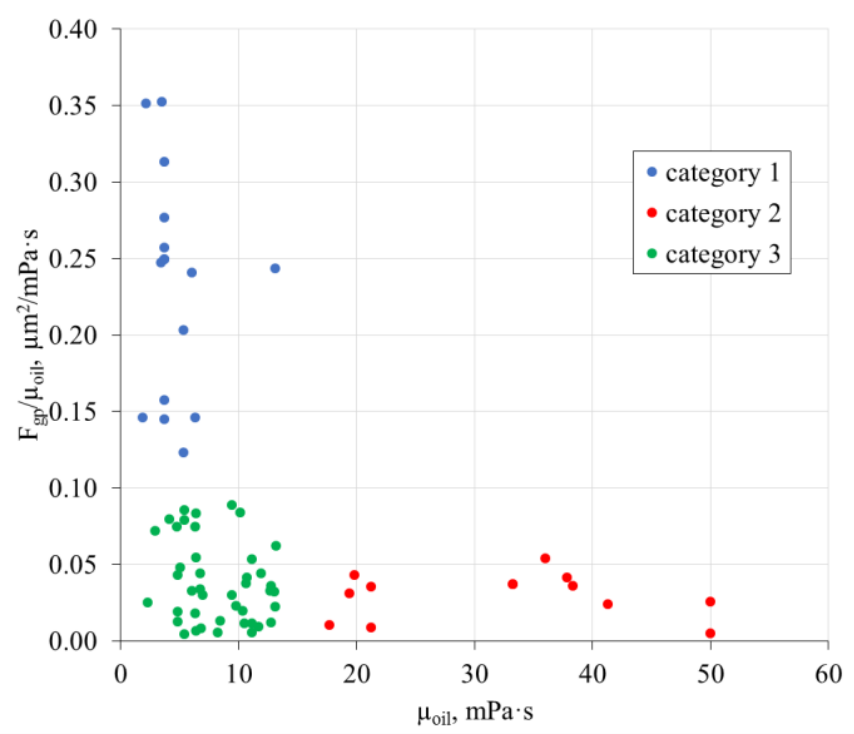

Fig. 3. The change of the mobility ratio depending on oil viscosity.

- the first one is located within the values interval of $R_{\text {mob }}$ from the maximum value of 0.353 to $0.123 \mu \mathrm{m}^{2} / \mathrm{mPa} \cdot \mathrm{s}$. When the oil viscosity increases, $R_{\text {mob }}$ changes more intensively;

- the second one is located within the interval of $R_{m o b}$ values corresponding to the change of $\mu_{\text {oil }}$ from 17.7 to 50 $\mathrm{mPa} \cdot \mathrm{s}$. The values of $\mathrm{R}_{\mathrm{mob}}$ change insignificantly when the oil viscosity increases;

- the third one has either a weak or absent relation between the $R_{\text {mob }}$ values and $\mu_{\text {oil }}$.

Within the coordinates of permeability, i.e. the mobility ratio (Fig. 4), the values of the outlined categories are quite independent from each other.

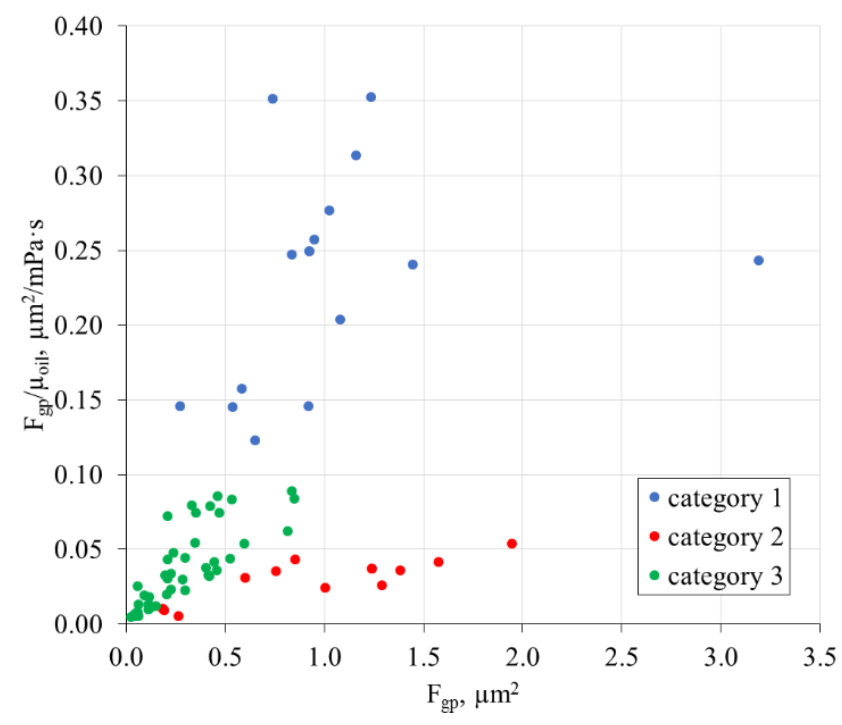

Fig. 4. The dependence of the mobility ratio on permeability.

The multilevel equations for the estimation of the oil displacement efficiency were obtained by using the stepwise regression analysis for the outlined groups (categories):

- for the first category

$\mathrm{E}_{\mathrm{D}}^{\mathrm{M} 1}=0.5883-0.3541 \mathrm{~F}_{\mathrm{rws}}+0.0291 \mathrm{~F}_{\mathrm{gp}}+0.2358\left(\mathrm{~F}_{\mathrm{gp}} / \mu_{\mathrm{oil}}\right),(6)$

where $\mathrm{R}^{2}=0.82, \mathrm{p}<10^{-4}, \mathrm{~N}=16$;

- for the second category

$\mathrm{E}_{\mathrm{D}}^{\mathrm{M} 2}=-0.5486-0.7384 \mathrm{~F}_{\mathrm{rws}}+1.9497 \mathrm{~F}_{\mathrm{p}}+0.3784 \rho$,

where $\mathrm{R}^{2}=0.85, \mathrm{p}<3.4 \cdot 10^{-4}, \mathrm{~N}=13$;

- for the third category

$\mathrm{E}_{\mathrm{D}}^{\mathrm{M} 3}=0.8217+0.9362\left(\mathrm{~F}_{\mathrm{gp}} / \mu_{\mathrm{oil}}\right)-0.1975 \mathrm{~F}_{\mathrm{rws}}-0.1161 \rho$

where $\mathrm{R}^{2}=0.65, \mathrm{p}<10^{-5}, \mathrm{~N}=42$.

In Figure 5, the model values of $E_{D}$ calculated by the equations (2-4) and the experimental values of $E_{D}$ for the first and second categories are quite close to the line of equal values. In both cases, the $\mathrm{r}$ correlation coefficients are equal to 0.91 and 0.93 , respectively, when $p<10^{-5}$. The correlation field of values of the third category, when $E_{D}<0.6$, lies primarily above the line of the equal values, i.e. it is shifted to the area of the model values; when $E_{D}>0.6$, it is shifted to the area of the experimental values. Thus, the authors can assume that the sample for the third category unites two categories of values with the border between them in the range of $E_{D}=0.6$.

Thus for this sample, the authors performed the stepwise regression analysis with the equations which have initially been built using three values $(\mathrm{N}=3)$, and then using four values $(\mathrm{N}=4)$ and so on up to $\mathrm{N}=42$ (Table 5). It allowed studying the influence of the parameters on the displacement efficiency in dynamics. 


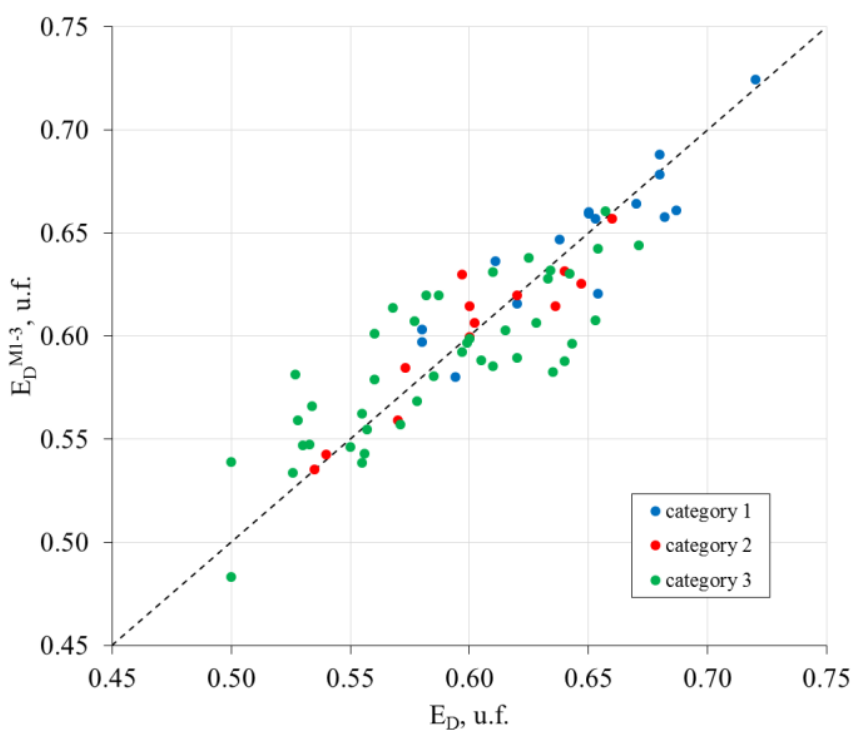

Fig. 5. The correlation field of ED model and experimental values for three categories.

TABLE 5. MULTILEVEL EQUATIONS OF THE STEPWISE REGRESSION ANALYSIS OF THE 3RD CATEGORY DATA FROM THE VISEAN TERRIGENOUS SEDIMENTS IN THE DEPOSITS OF THE BASHKIR FORMATION

\begin{tabular}{|c|lc|}
$\mathbf{N}$ & \multicolumn{1}{|c}{ Equation } & Coefficient \\
\hline 3 & $\mathrm{E}_{\mathrm{D}}{ }^{\mathrm{M}}=-0.4985+0.4613 \mathrm{c}$ & $\begin{array}{c}\mathrm{R}^{2}=0.98 \\
\mathrm{p}<0.099\end{array}$ \\
\hline 4 & $\mathrm{E}_{\mathrm{D}}{ }^{\mathrm{M}}=0.5314-0.0753 \mathrm{~F}_{\mathrm{rws}}$ & $\begin{array}{c}\mathrm{R}^{2}=0.58 \\
\mathrm{p}<0.236\end{array}$ \\
\hline 5 & $\mathrm{E}_{\mathrm{D}}{ }^{\mathrm{M}}=0.5337-0.0813 \mathrm{~F}_{\mathrm{rws}}$ & $\begin{array}{c}\mathrm{R}^{2}=0.65 \\
\mathrm{p}<0.101\end{array}$ \\
\hline$\ldots$ & $\cdots$ & $\ldots$ \\
\hline 41 & $\mathrm{E}_{\mathrm{D}}{ }^{\mathrm{M}}=0.9070-0.0628\left(\mathrm{~F}_{\mathrm{gp}} / \mathrm{M}_{\text {oil }}\right)-0.2721 \mathrm{~F}_{\mathrm{rws}}-0.1262 \mathrm{c}-$ & $\begin{array}{c}\mathrm{R}^{2}=0.67 \\
\mathrm{p}<10^{-5}\end{array}$ \\
\hline 42 & $\mathrm{E}_{\mathrm{D}}{ }^{\mathrm{M}}=0.8217+0.9362\left(\mathrm{~F}_{\mathrm{gp}} / \mathrm{M}_{\text {oil }}\right)-0.1975 \mathrm{~F}_{\mathrm{rws}}-0.1161 \mathrm{c}$ & $\begin{array}{c}\mathrm{R}^{2}=0.65 \\
\mathrm{p}<10^{-5}\end{array}$ \\
\hline
\end{tabular}

In the obtained regression equations of up to $\mathrm{N}=20$ $\left(E_{D}<0.6\right)$, the capacity parameter "residual water saturation $\mathrm{F}_{\text {rws }}$ " is present at the first place; then it is replaced with the filtration characteristic "mobility ratio $\mathrm{F}_{\mathrm{gp}} / \mu_{\mathrm{oil}}$ ", i.e. $\mathrm{E}_{\mathrm{D}}$ is influenced by different parameters in the groups. It is also confirmed by the values of the regression coefficients related to the parameters in the equations. Thus, the dependences of the coefficients' values on $\mathrm{E}_{\mathrm{D}}$, when $\mathrm{F}_{\mathrm{rws}}$ and $\mu_{\text {oil }}$ have extremities at the range of $E_{D}=0.61$ (Fig. 6).

For the dependence of the determination coefficient $\mathrm{R}^{2}$ on the oil displacement efficiency (Fig. 7), the extremity of the diagram is observed, when $E_{D}=0.60$, i.e. prior to this value, the approximation accuracy starts to increase, and after it, it starts to decrease. It indicates that the parameters, properly "operating" in the left part of the diagram, "operate" worse in the right part of the diagram.

In this context, the values of $\mathrm{R}^{2}$ close to one were not considered as they correspond to the equations which are built based on the minimal amount of data.

The extremum at the range of $\mathrm{E}_{\mathrm{D}}=0.55$ can be explained by the local changes of parameters in the equations and introduction of the "volume density of rocks $\rho$ " parameter.

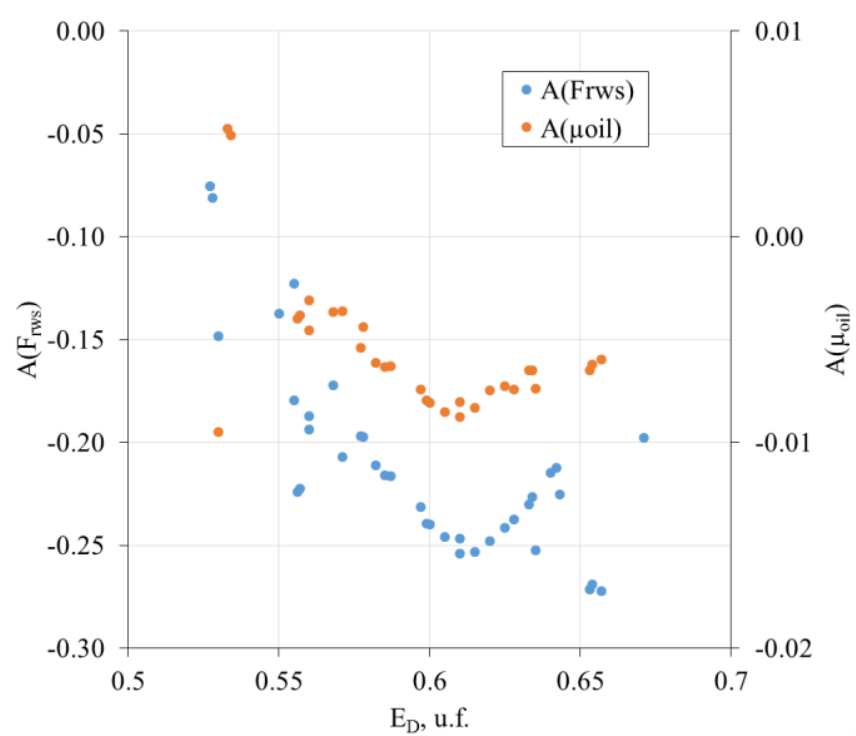

Fig. 6. Dependences of coefficients' values at $F_{r w s}$ and $\mu_{\text {oil }}$ on $E_{D}$ in the equations with the stepwise regression analysis for the Visean terrigenous sediments.

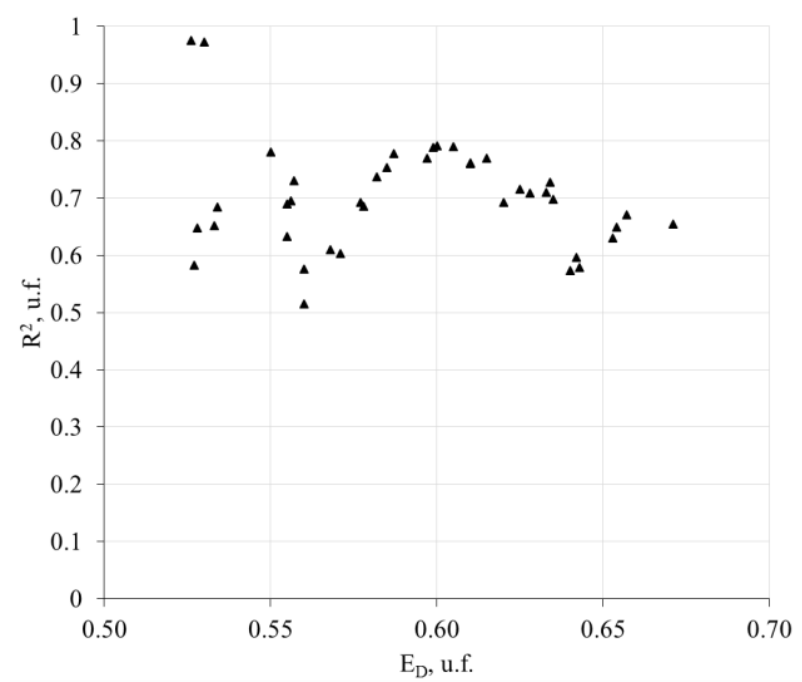

Fig. 7. Dependence of the determination coefficient values on $E_{D}$ during the stepwise regression analysis for the Visean terrigenous sediments in the fields of the Bashkir formation.

Based on the conducted analysis, it was established that the sample of the third category includes two sub-categories with a conventional border between them at the range of $\mathrm{E}_{\mathrm{D}}=0.6$, to which the maximum value of $\mathrm{R}^{2}$ corresponds. The data affiliation with the first or second sub-category is more precisely determined with the help of the linear discriminatory analysis (LDA). The linear discriminatory function (LDF) that subdivided the sample by the values of the mobility ratio, residual water saturation and density has the following form

$\mathrm{Z}=-15.5681+91.7717\left(\mathrm{~F}_{\mathrm{gp}} / \mu_{\mathrm{oil}}\right)+6.3586 \mathrm{~F}_{\mathrm{rws}}+5.3255 \rho,(9)$ where $\mathrm{R}^{2}=0.79, \mathrm{p}<10^{-5}$.

When the values of $Z<1.2$, the data pertain to the first subcategory; when $\mathrm{Z}>1.2$, the data pertain to the second sub- 
category. For the outlined sub-categories, the regression equations were obtained for $\mathrm{E}_{\mathrm{D}}$ :

- for the first sub-category of the third category

$\mathrm{E}_{\mathrm{D}}^{\mathrm{M} 3-1}=0.5501-0.1500 \mathrm{~F}_{\mathrm{rws}}+1.7990\left(\mathrm{~F}_{\mathrm{gp}} / \mu_{\mathrm{oil}}\right)$,

where $\mathrm{R}^{2}=0.62, \mathrm{p}<10^{-5}, \mathrm{~N}=31$;

- for the second sub-category of the third category

$\mathrm{E}_{\mathrm{D}}^{\mathrm{M} 3-2}=0.5214+2.0426\left(\mathrm{~F}_{\mathrm{gp}} / \mu_{\mathrm{oil}}\right)-0.6285 \mathrm{~F}_{\mathrm{rws}}$,

where $\mathrm{R}^{2}=0.77, \mathrm{p}<5.18 \cdot 10^{-3}, \mathrm{~N}=11$.

As a result of outlining the sub-categories, the correlation field is evenly distributed along the line of equal values (Fig. $8 \mathrm{~b}$ ) and consists of three ranges, smoothly running into one another. When $E_{D}<0.57$, it is the range of values of the first sub-category; when $\mathrm{E}_{\mathrm{D}}>0.63$, it is the range of values of the second sub-category; when $0.57<\mathrm{E}_{\mathrm{D}}<0.6$, it is the transition range from the first to the second sub-category. In general, the estimation accuracy of the model values of $E_{D}$ for the third category increased, as compared with the variant without the sub-categories (Fig. 8a).

Thus, it became possible to describe the sample for the Visean sediments in the fields of the Bashkir formation with four regression equations (3), (4), (10) and (11), which allowed reducing the relative error of evaluation of the model values of $E_{D}$ (Fig. 9).

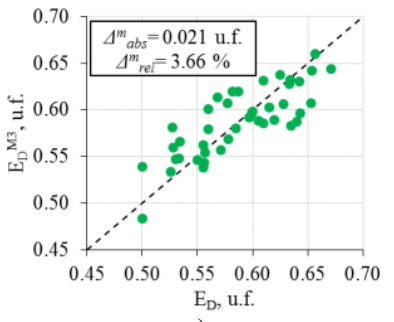

a)

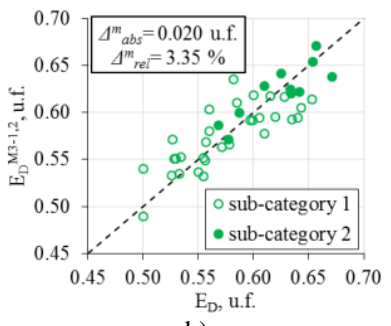

b)
Fig. 8. The comparison of the model and experimental values of ED for the third category before (a) and after (b) sub-categorizing.

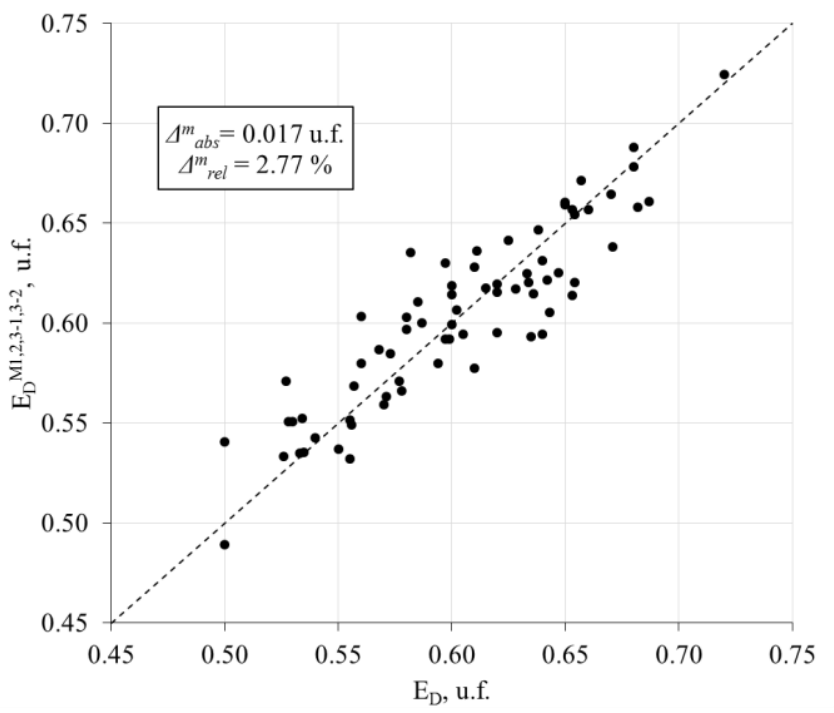

Fig. 9. Comparison of $E_{D}$ model and experimental data after categorizing and sub-categorizing in the initial sample for the Visean terrigenous sediments in the fields of the Bashkir formation.

\section{STATISTICAL MODELS FOR ESTIMATION OF DISPLACEMENT EFFICIENCY OF PRODUCTIVE SEDIMENTS OF SOLIKAMSK DEPRESSION OIL}

\section{$\underline{\text { Visean terrigenous sediments }}$}

The initial sample for the Visean terrigenous sediments of Solikamsk depression consists of 46 determinations of the displacement efficiency. Based on the sampling data, the correlation fields have been built and $\mathrm{r}$ correlation coefficients have been found (Table 6).

TABLE 6. CORELATION MATRIX FOR SAMPLES OF THE VISEAN TERRIGENOUS SEDIMENTS OF SOLIKAMSK DEPRESSION

\begin{tabular}{|c|c|c|c|c|c|c|c|c|}
\hline & $\mathbf{F}_{\mathbf{p}}$ & $\mathbf{F}_{\mathrm{gp}}$ & $\mathbf{F}_{\text {rws }}$ & p & $\mu_{\text {oil }}$ & $\mathbf{F}_{\mathbf{p}} / \mathbf{p}$ & $\mathrm{F}_{\mathrm{gp}} / \boldsymbol{\mu}_{\mathrm{oil}}$ & $\mathbf{E}_{\mathbf{D}}$ \\
\hline $\mathbf{F}_{\mathbf{p}}$ & 1.00 & $\frac{0.81}{0.000}$ & $\frac{-0.66}{0.000}$ & $\frac{-0.96}{0.000}$ & $\frac{0.04}{0.776}$ & $\frac{0.99}{0.000}$ & $\frac{0.67}{0.000}$ & $\frac{0.65}{0.000}$ \\
\hline $\mathbf{F}_{\mathrm{gp}}$ & & 1.00 & $\frac{-0.54}{0.000}$ & $\frac{-0.72}{0.000}$ & $\frac{-0.05}{0.766}$ & $\frac{0.82}{0.000}$ & $\frac{0.91}{0.000}$ & $\frac{0.61}{0.000}$ \\
\hline $\mathbf{F}_{\text {rws }}$ & & & 1.00 & $\frac{0.69}{0.000}$ & $\frac{-0.20}{0.184}$ & $\frac{-0.66}{0.000}$ & $\frac{-0.42}{0.004}$ & $\frac{-0.76}{0.000}$ \\
\hline $\mathbf{p}$ & & & & 1.00 & $\frac{-0.01}{0.926}$ & $\frac{-0.96}{0.000}$ & $\frac{-0.60}{0.003}$ & $\frac{-0.61}{0.000}$ \\
\hline $\boldsymbol{\mu}_{\text {oil }}$ & & & & & 1.00 & $\underline{0.03}$ & $\frac{-0.28}{0.058}$ & $\frac{-0.04}{0.792}$ \\
\hline $\mathbf{F}_{\mathbf{p}} / \mathbf{c}$ & & & & & & 1.00 & $\frac{0.68}{0.007}$ & $\frac{0.66}{0.000}$ \\
\hline $\mathbf{F}_{\mathrm{gp}} / \boldsymbol{\mu}_{\text {oil }}$ & & & & & & & 1.00 & $\underline{0.55}$ \\
\hline $\mathbf{E}_{\mathbf{D}}$ & & & & & & & & 1.00 \\
\hline
\end{tabular}

Table 6 shows that the studied parameters, except for the oil viscosity, correlate well with each other. The following multidimensional regression equation is made for the whole sample

$\mathrm{E}_{\mathrm{D}}{ }^{\mathrm{M}}=0.6978-0.4725 \mathrm{~F}_{\mathrm{rws}}+0.0943\left(\mathrm{~F}_{\mathrm{gp}} / \mu_{\mathrm{oil}}\right)$,

where $\mathrm{R}^{2}=0.69, \mathrm{p}<10^{-4}, \mathrm{~N}=46$.

The comparison of the values of the depression efficiency, which has been estimated according to equation (12) and experimental values (Fig. 10a), shows that the correlation field when $E_{D}<0.62$ (on the left of the red line) has a wide range of values relative to the right-hand side of the field, where the model values of $\mathrm{E}_{\mathrm{D}}$ are mostly lower than the experimental ones.

As in the case with the Visean terrigenous sediments of the Bashkir formation, the authors can assume that $\mathrm{E}_{\mathrm{D}}$ is affected by different parameters of the correlation field in the left and right parts of the correlation field relative to the red line.

It is confirmed by the fact that the dependence of the determination coefficient $\mathrm{R}^{2}$ on $\mathrm{E}_{\mathrm{D}}$ (Fig. 11) which has been obtained by the stepwise regression analysis including the equations at first, for $\mathrm{N}=3$ values of the sample, then for $\mathrm{N}=4$ and so on up to $\mathrm{N}=46$. This dependence has a tendency to become decreased up to $\mathrm{E}_{\mathrm{D}}=0.62$; and after the extremity, it tends to grow and divides the sample into 2 categories.

Discriminant function $\mathrm{Z}$ which divided the sample into two categories has the following form:

$\mathrm{Z}=-56.7220+132.0232 \mathrm{~F}_{\mathrm{p}}-13.2649 \mathrm{~F}_{\mathrm{rws}}-5.3172 \mathrm{~F}_{\mathrm{gp}}+$ 


$$
+17.8673 \rho
$$

where $\mathrm{R}^{2}=0.77, \mathrm{p}<10^{-5}, \mathrm{~N}=46$.

The data when $\mathrm{Z}<-0.5$ refer to the first category; when $\mathrm{Z}$ $>-0.5$, the data refer to the second category. After the selection of the two classes in the original sample, the linear regression equations are obtained

- for the first category

$$
\begin{aligned}
\mathrm{E}_{\mathrm{D}}{ }^{\mathrm{M} 1}=- & 0.5483-0.2514 \mathrm{~F}_{\mathrm{rws}}+0.4811 \rho+2.6959\left(\mathrm{~F}_{\mathrm{gp}} / \mu_{\text {oil }}\right)+ \\
& +1.1552 \mathrm{~F}_{\mathrm{gp}}+0.0159 \mu_{\text {oil }}
\end{aligned}
$$

where $\mathrm{R}^{2}=0.79, \mathrm{p}<1.94 \cdot 10^{-3}, \mathrm{~N}=18$;

- for the second category

$$
\begin{aligned}
\mathrm{E}_{\mathrm{D}}{ }^{\mathrm{M} 2}= & 0.7885-0.0759\left(\mathrm{~F}_{\mathrm{gp}} / \mu_{\mathrm{oil}}\right)-0.7088 \mathrm{~F}_{\mathrm{rws}}-0.0203 \mu_{\text {oil }}+ \\
& +0.0671 \mathrm{~F}_{\mathrm{gp}}
\end{aligned}
$$

where $\mathrm{R}^{2}=0.84, \mathrm{p}<10^{-5}, \mathrm{~N}=28$.

The comparison of the model and experimental values of $\mathrm{E}_{\mathrm{D}}$ (Fig. 10b) has revealed that they control each other well $(r=0.93)$. At the same time, the error in estimating the model values of the displacement efficiency decreased in comparison to the variant without the categorization.

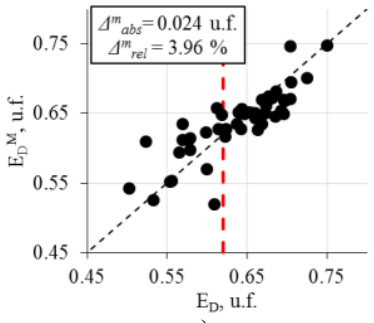

a)

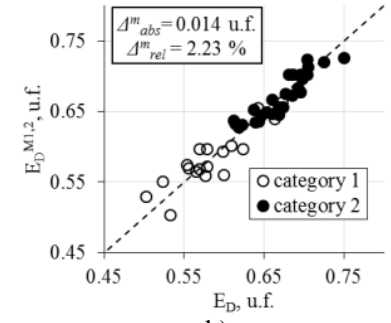

b)
Fig. 10. Comparison of experimental and model values of $E_{D}$ before (a) and after (b) categorizing in the initial sample for the Visean terrigenous sediments of the Solikamsk depression.

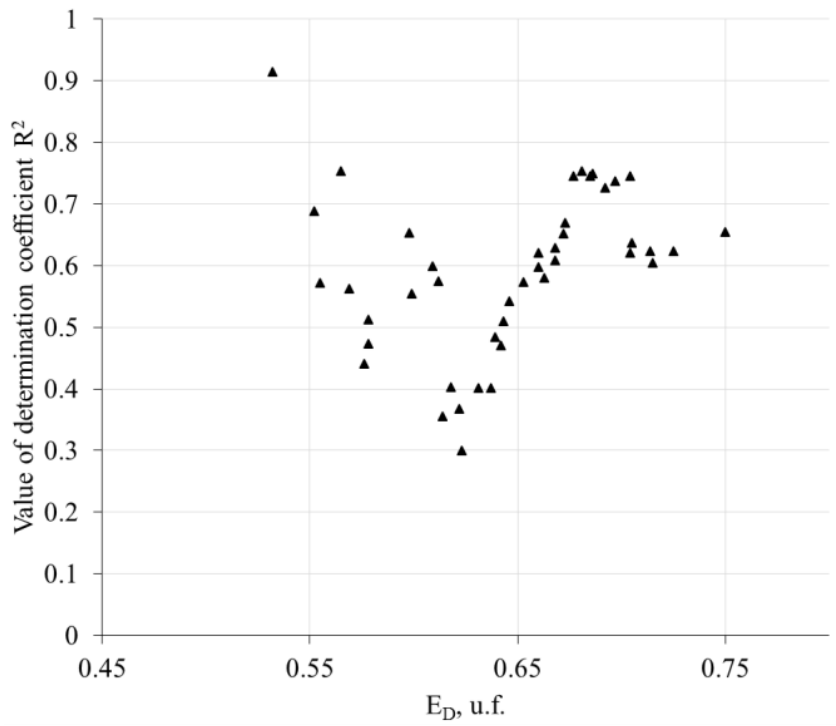

Fig. 11. Dependence of the determination coefficient on $E_{D}$ during the stepwise regression analysis for the Visean terrigenous sediments of the Solikamsk depression.

\section{Bashkir carbonate sediments}

The equations for the two classes of Bashkir carbonate deposits of the Solikamsk depression have been obtained in a similar way

- for the first category

$$
\begin{aligned}
\mathrm{E}_{\mathrm{D}}^{\mathrm{M} 1}= & -1.1483-5.6251 \mathrm{~F}_{\mathrm{gp}}+0.1718 \mu_{\mathrm{oil}}+ \\
& +16.1795\left(\mathrm{~F}_{\mathrm{gp}} / \mu_{\mathrm{oil}}\right)+0.4404 \rho-0.1534 \mathrm{~F}_{\mathrm{rws}}
\end{aligned}
$$

where $\mathrm{R}^{2}=0.99$ and $\mathrm{p}<0.0026$;

- for the second category

$\mathrm{E}_{\mathrm{D}}^{\mathrm{M} 2}=0.5712+0.1914 \mathrm{~F}_{\mathrm{gp}}+0.2823\left(\mathrm{~F}_{\mathrm{gp}} / \mu_{\mathrm{oil}}\right)$

where $\mathrm{R}^{2}=0.40$ and $\mathrm{p}<0.077$.

In this case, the first category includes the data for which the value of discriminant function (18) is more than 0.5 , and for the second category it will be so, when $\mathrm{Z}<0,5$ :

$$
\begin{aligned}
Z & =101.442-191.381 F_{p}+29.490 F_{r w s}+13.620 F_{g p}- \\
& -35.118 \rho
\end{aligned}
$$

where $\mathrm{R}^{2}=0.84$ and $\mathrm{p}<7 \cdot 10^{-6}$.

The model values of $E_{D}$ which have been estimated according to (16) and (17) correlate well with the experimental ones (Fig. 12b).

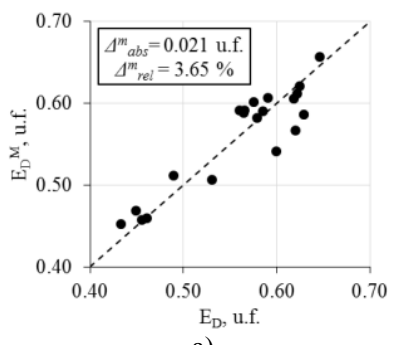

a)

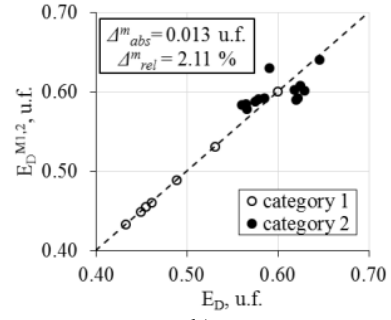

b)
Fig. 12. Comparison of experimental and model values of $E_{D}$ before (a) and after (b) categorizing in the initial sample for the Bashkir carbonate sediments of the Solikamsk depression.

\section{CONCLUSIONS}

The research results have made it possible to establish the following conclusions.

1. In terrigenous sediments, the value of the oil displacement efficiency is mainly influenced by the residual water saturation or the value of the initial hydrocarbon saturation of rocks.

2. In general, the displacement efficiency in carbonate rocks is formed by means of their porosity and permeability properties.

3. The proposed method allows estimating the values of the oil displacement efficiency without its laboratory determination with the use of the data from standard analyses of core and oil viscosity. 
4. The "oil viscosity" parameter takes part in the formation of the displacement efficiency values in both terrigenous and carbonate deposits.

\section{References}

[1] OST 39-195-86. Oil. Method for Determination of Water Flood Oil Recovery Factor in Laboratory Conditions. - Moscow: Minnefteprom, 1986 p. 19.

[2] P. A. Owusu, L. De Hua, R. D. Nagre "Prognostication of water flooding performance in communicating layered reservoir", International Journal of Earth Sciences and Engineering, vol. 8(5), pp. 2004-2010, 2015.

[3] I.S. Putilov, N.N. Barkovsky, O.I. Yakimov, T.V. Chabina, N.A. Cherepanova "Complex Approach to the Laboratory Studies of Chemical Reagents Applied for the Control of Reservoir Coverage with Water Flood", Oil and Gas Engineering, no. 4, pp. 72-75, 2017.

[4] I.S. Putilov, P.N. Rekhachev, I.P. Gurbatova, N.N. Barkovsky, O.I. Yakimov, O.A. Morozyuk "Era of Whole Core at Laboratory Researches of Oil Recovery Improvement Techniques", Bulletin of Perm National Research Polytechnic University. Geology. Oil and Gas Engineering and Mining, vol. 15, no. 19, pp. 155-164, 2016.

[5] S.V. Melekhin, N.N. Mikhailov "Experimental Study of Residual Oil Mobilisation at Water Flooding of Carbonate Reservoir Rocks", Oil and Gas Engineering, no. 8, pp. 72-76, 2015.

[6] A.V. Raspopov, G.P. Khizhnyak "Substantiation of Water Flood Oil Displacement Factor with the Use of the Research Results from Similar Facilities", Geology, Geophysics and Development of Oil and Gas Fields, no. 6, pp. 39-43, 2009.

[7] G.P. Khizhnyak, A.V. Raspopov, A.A. Efimov "Methodological Approaches at Substantiation of Oil Displacement Factor in Different Geological and Physical Conditions", Geology, Geophysics and Development of Oil and Gas Fields, no. 10, pp. 32-35, 2009.

[8] M. A. Andersen, B. Duncan, R. McLin "Core truth in formation evaluation", Oilfield Review, no. 2, pp. 16-25, 2013.

[9] J. Davis, Statistics and Data Analysis in Geology, Moscow: Mir, 1977, p. 353.

[10] G.N. Chumakov "Probability Estimate of Applying the Method of Water Cyclical Pumping Down into reservoir", Bulletin of Perm National Research Polytechnic University Geology. Oil and Gas and Mining Engineering. no. 13, pp. 49-58, 2014. DOI: 10.15593/22249923/2014.13.5. 